Check for updates

Cite this: RSC Adv., 2020, 10, 30139

Received 24th May 2020

Accepted 23rd July 2020

DOI: $10.1039 / \mathrm{dOra04587j}$

rsc.li/rsc-advances

\section{Bio-inspired facile fabrication of silver nanoparticles from in vitro grown shoots of Tamarix nilotica: explication of its potential in impeding growth and biofilms of Listeria monocytogenes and assessment of wound healing ability}

\author{
Nasser A. Al-Shabib, ${ }^{* a}$ Fohad Mabood Husain, (DD *a Mohammad Nadeem, \\ Mohd Shahnawaz Khan, ${ }^{c}$ Fahad Al-Qurainy, ${ }^{b}$ Abdullah A. Alyousef, ${ }^{d}$ \\ Mohammed Arshad, ${ }^{d}$ Altaf Khan, ${ }^{e}$ Javed Masood Khan, ${ }^{\text {a }}$ Pravej Alam, ${ }^{f}$ \\ Thamer Albalawi ${ }^{f}$ and Syed Ali Shahzad ${ }^{a}$
}

\begin{abstract}
Novel, safe, and effective antilisterial agents are required in order to prevent Listeria monocytogenes infections and maintain food safety. This study synthesized silver nanoparticles (AgNPs) from the shoot extract of in vitro-grown Tamarix nilotica (TN) and characterized them using X-ray diffraction, Fourier transform infrared spectroscopy, UV-visible spectroscopy, dynamic light scattering, scanning electron microscopy (SEM), energy-dispersive X-ray spectroscopy (EDXS), and transmission electron microscopy (TEM). We also assessed the antilisterial potential of the synthesized TN-AgNPs by determining the minimum inhibitory concentration (MIC) and minimum bactericidal concentration (MBC) against two strains of $L$. monocytogenes and L. innocua. TN-AgNPs $(2 \times M I C s)$ showed a significant decrease in growth in all Listeria test strains. Release of cellular content and cell morphology analysis of TN-AgNPtreated bacterial cells demonstrated the mechanism of bactericidal activity of AgNPs. In addition, TNAgNPs induced a significant decrease in swimming motility (62-71\%), biofilm formation (57-64\%), and preformed biofilms (48-58\%) in all Listeria test strains at sub-inhibitory concentrations. Microtitre plate assay results for biofilm inhibition were confirmed by SEM and CLSM visualization of TN-AgNP-treated and TN-AgNP-untreated Listeria test strains. TN-AgNPs also showed wound-healing activity in MCF-7 cells by inhibiting cell migration in a scratch plate assay. TN-AgNP-induced enhanced reactive oxygen species generation in treated cells could be a plausible reason for the biofilm inhibitory activity of AgNPs. TN-AgNPs having antilisterial, antibiofilm, and wound-healing properties can be effectively used to prevent $L$. monocytogenes infections in the food industry and healthcare.
\end{abstract}

\section{Introduction}

Listeria monocytogenes is a key foodborne human pathogen and, because of its high pathogenicity, is considered one of the most harmful bacteria associated with the food industry. The most common sources of listerial infections are processed and readyto-eat frozen foods. ${ }^{1}$ Listeriosis has a low incidence rate but can be lethal to susceptible populations, such as pregnant women, newborns, the elderly, and immunocompromised people; in immunocompetent people, listeriosis is non-invasive. It can cause mild gastroenteritis to potentially fatal infections, such as septicemia, encephalitis, and meningitis, depending on the individual's vulnerability. ${ }^{2}$

Listeria is ubiquitous in nature and so contaminates food during various stages of processing and distribution. Ready-to- 
eat foods are at high risk of Listeria infections because of a lack of effective decontamination methods that can destroy viable $L$. monocytogenes cells or because of recontamination post decontamination. ${ }^{3,4}$ In addition, Listeria spp. flourish at $0-4{ }^{\circ} \mathrm{C}$, and their tolerance to commonly used food preservatives is a big challenge in maintaining food safety. Therefore, temperature control is of great importance in controlling L. monocytogenes growth in fast food, and even a small inoculum during production, transport, or retail or at the consumer level can lead to a significant pathogenic burden. ${ }^{5}$ Biofilm formation by $L$. monocytogenes on abiotic and biotic surfaces in a foodprocessing environment accounts for most of the contamination of processed foods. ${ }^{6}$ Decontamination of surfaces on which biofilm formation occurs is a tough challenge because bacteria in biofilms are more resistant to detergents, chemicals, and disinfectants compared to their planktonic forms. Biofilms help bacteria survive in unsuitable environmental settings such as acidity, low temperature, and high salinity. ${ }^{7}$ Therefore, biofilm formation helps L. monocytogenes withstand stress and enhances its viability in unfavorable conditions. ${ }^{8}$

The development of a novel, safe, and effective antilisterial agent is required in order to prevent $L$. monocytogenes infections and maintain food safety. Nanoparticles (NPs) possess unique physicochemical, catalytic, electronic, and biological properties and are used in biosensing, catalysis, drug delivery, cosmetics, and various biomedical applications. ${ }^{9}$ NP synthesis using chemical and physical methods is hazardous because huge amounts of chemicals are generated as by-products. In addition, NP synthesis is expensive, time consuming, and energy consuming. ${ }^{10}$ Green or bioinspired NP synthesis uses biological sources for producing metallic NPs through a rapid, economical, and eco-friendly process. Plant extracts and microbes are extensively used to produce NPs of desired shapes and sizes. ${ }^{\mathbf{1 1 , 1 2}}$ However, culture time and cross-contamination of microbial cultures limit their use as substrates for NP synthesis. In contrast, the abundant availability of plant material makes it a most suitable candidate for NP synthesis. ${ }^{13}$ Almost all plant parts, ranging from roots, to leaves, peel, fruits, and seeds, can be used as reducing and capping agents for metallic NP synthesis. ${ }^{\mathbf{1 4}}$ Plant substrates act as effective reductants because of the presence of an array of phytochemicals, proteins, antioxidants, and amino acids. ${ }^{15}$

Silver nanoparticles (AgNPs) have broad-spectrum bactericidal and fungicidal potential and do not induce resistance in bacteria. ${ }^{16}$ The antimicrobial activity of AgNPs is due to their high surface-area-to-volume ratio and slow, sustained release of $\mathrm{Ag}^{+}$into microbial cells. ${ }^{17}$ However, there are few reports on the antibacterial and antibiofilm activity of AgNPs against Listeria spp.

Tamarix nilotica (Ehrenb.; TN) Bunge belongs to the Tamaricaceae family and is a native shrub of the Middle East and North Africa. In ancient Egypt, Bunge was used to treat fever, migraine, and irritation and as an antiseptic and sexual enhancer. Various parts of TN are used in traditional medicine; for example, cooked leaves and young branches are used for edema of the spleen, leaves blended in ginger are used for uterine diseases, and bark bubbled in water with vinegar is used as a moisturizer against lice. ${ }^{18}$ The plant's antioxidant activity due to the presence of various phenolic compounds is also well established. ${ }^{19}$

However, TN has not yet been studied for NP synthesis, and using such a medicinally important plant for NP synthesis would be an added advantage. Therefore, this study synthesized AgNPs from in vitro-grown shoots of TN and characterized them using X-ray diffraction (XRD), Fourier transform infrared (FTIR) spectroscopy, UV-visible spectroscopy, dynamic light scattering (DLS), scanning electron microscopy (SEM), energy-dispersive $\mathrm{X}$-ray spectroscopy (EDX), transmission electron microscopy (TEM), and confocal laser scanning microscopy (CLSM) to assess their antilisterial and biofilm inhibitory potential against two strains of $L$. monocytogenes and one strain of L. innocua. We also investigated the plausible mechanism of action of AgNPs against Listeria spp. In addition, we explored the wound-healing potential of AgNPs using scratch plate assay.

\section{Material and methods}

\subsection{Listeria strains}

Listeria monocytogenes ATCC 19114, L. monocytogenes ATCC 13932 and L. innocua 33090 were used in present study. All cultures were stored at $-80{ }^{\circ} \mathrm{C}$ and were grown in Tryptose Soy broth (TSB) (Oxoid, UK) at $37^{\circ} \mathrm{C}$.

\subsection{Preparation of Tamarix nilotica shoots}

Explants of Tamarix nilotica were washed for $10 \mathrm{~min}$ under running water, sterilized in ethanol $70 \%(\mathrm{v} / \mathrm{v})$ for $1 \mathrm{~min}$ and plunged twice (10 min each) in Chlorox (3.0-4.0\% accessible chloride) with 5-6 drops of Teepol. Thereafter, explant material was exposed to fungicide carbendazim (1\%, Bayer, Turkey) for $10 \mathrm{~min}$ followed by three washes in sterile water ( $5 \mathrm{~min}$ each). Sterilized explants ( $1 \mathrm{~cm}$ long cuttings with axillary bud) were put on MS medium containing TDZ (thidiazuron) in thirty phyta jars with $50 \mathrm{ml}$ medium containing five explants each. Cultures were incubated in a growth chamber at $25 \pm 1{ }^{\circ} \mathrm{C}$ with a $16 \mathrm{~h}$ photoperiod and irradiance of $98 \mu \mathrm{mol} \mathrm{m}{ }^{-2} \mathrm{~s}^{-1}$ enhanced by Phillips L36W/21 lights. ${ }^{19}$

\subsection{Preparation of extract}

In vitro grown shoots of $T$. nilotica were collected, washed thoroughly to remove all attached growth media and disinfected with ethanol (70\%). Approx. $20 \mathrm{~g}$ of the shoots were dissolved in $100 \mathrm{ml}$ of double distilled water and boiled for $5 \mathrm{~min}$. The obtained extract was passed through Whatman No. 1 filter paper (Maidstone, UK) and centrifuged at $5000 \mathrm{rpm}$ for 5 min to sediment out residual particles. This extract of Tamarix nilotica was used for the bio-fabrication of AgNPs. ${ }^{20}$

\subsection{Bio-inspired synthesis of TN-AgNPs}

Synthesis was initiated at room temperature by mixing the extract $(1 \mathrm{ml})$ with $1 \mathrm{mM}$ aqueous silver nitrate $(20 \mathrm{ml})$ solution. The transformation of colorless suspension to dark brown color was indicative of the formation of NPs by reduction of $\mathrm{AgNO}_{3}$ to silver ion $\left(\mathrm{Ag}^{+}\right)$. Centrifugation (10 $000 \mathrm{rpm}, 25 \mathrm{~min}$ ) was done 
to harvest the AgNPs. Pellet was washed and dried overnight at $60{ }^{\circ} \mathrm{C} .{ }^{12}$

\subsection{Characterization of TN-AgNPs}

The bio-fabricated AgNPs were characterized using X-ray diffraction (XRD) in the 2 theta range $\left(10-80^{\circ}\right)$ using a PANalytical diffractometer. Fourier transform infrared (FTIR) spectra was obtained in the range of $4000-400 \mathrm{~cm}^{-1}$ to assess the functional groups involved in the synthesis of nanoparticles. Water diluted samples of fabricated nanoparticles were scanned between $300-700 \mathrm{~nm}$ and absorption spectrum was recorded on a UV-visible spectrophotometer (ELICO SL159). The average size of the particle, polydispersity index (PDI), and zeta potential of the nanoparticles were determined by dynamic light scattering (DLS) on a Zetasizer HPPS-5001 (Malvern, UK) at $25^{\circ} \mathrm{C}$ at a scattering angle of $90^{\circ}$.

Further, morphological characterization of the fabricated AgNPs was accomplished using scanning electron microscopy (SEM) and transmission electron microscopy (TEM). SEM of silver nanoparticles was performed using, SEM, JSM-7001F, JEOL, Japan equipped with energy dispersive X-ray spectroscopy (EDS). Finely powdered silver nanoparticles were place onto sample holder and visualized under scanning electron microscope at different magnifications. Transmission electron microscopy (TEM) was performed using JEOL 2010, Japan. The aqueous suspension of silver nanoparticles was made in double distilled water and sonicated to make an even dispersion. Ten microliter of sample was placed on TEM grid and left to air dry overnight at room temperature. The images were captured at varying magnifications.

\subsection{Antilisterial activity of TN-AgNPs}

Antilisterial activity in terms of minimum inhibitory concentration (MIC) and minimum bactericidal concentration (MBC) of the AgNPs was determined using the microbroth dilution method. ${ }^{21}$ Briefly, $100 \mu \mathrm{l}$ of Listeria cultures were added to each well of 96 well microtitre plate and two fold dilutions of AgNPs (concentrations ranging from $0.5-128 \mu \mathrm{g} \mathrm{ml}^{-1}$ ) were added to each well. Plates were incubated at $37{ }^{\circ} \mathrm{C}$ and observed for growth.

Growth kinetics studies at $2 \times$ MIC of TN-AgNPs were performed to further study the antibacterial activity against all the three strains of Listeria spp. Effect on growth was observed in terms of the optical density at $600 \mathrm{~nm}$. Bacteria both untreated and treated $(2 \times$ MIC) were grown in Tryptic soy broth (TSB) in $100 \mathrm{ml}$ flasks and $1 \mathrm{ml}$ were withdrawn at an interval of $2 \mathrm{~h}$ and optical density was measured. ${ }^{12}$

\subsection{Loss of cellular content}

Cellular content in the supernatant of TN-AgNPs treated and untreated cultures of test pathogen bacteria was determined by method described earlier. ${ }^{22,23}$ Overnight grown cultures of Listeria were centrifuged, washed thrice and suspended in MES buffer ( $\mathrm{pH}$ 5.5). TN-AgNPs $(2 \times \mathrm{MIC})$ were added to the suspension and incubated for $5 \mathrm{~h}$, while suspension without the amendment of AgNPs were used as control. Suspension was passed through $0.22 \mu \mathrm{m}$ filter and absorption was read at $260 \mathrm{~nm}$.

\subsection{Scanning electron microscopic (SEM) examination of cell surface morphology}

Cell surface morphology of TN-AgNPs treated and untreated bacteria was observed under Scanning electron microscope (JSM-7001F, JEOL, Japan). Bacteria $(1 \mathrm{ml})$ were centrifuged (5000 rpm, $10 \mathrm{~min}$ ), resulting pellet was washed thrice. Subsequently, the washed cells were fixed with $2.5 \%$ glutaraldehyde and incubated overnight at $4{ }^{\circ} \mathrm{C}$. Furthermore, samples were again washed three times and were post fixed with osmium tetraoxide for $60 \mathrm{~min}$. After post fixation, cells were again rinsed and subjected to dehydration using graded ethanol series $(25 \%$, $50 \%, 70 \%, 90 \%$ and $100 \%$ ). Dehydrated samples were gold coated by sputter coater and analyzed under SEM.

\subsection{Swimming assay}

Swimming motility of the test bacteria was assessed on LuriaBertani (LB) containing 0.3\% agar. AgNPs were amended to the agar medium to obtain desired sub-inhibitory concentrations against L. monocytogenes 19114, L. monocytogenes 13932 and. $L$. innocua 33090. NPs amended plates were dried at room temperature for half an hour and then $5 \mu \mathrm{l}$ of the bacteria were point inoculated on the surface of their respective plates. Inoculated plates were incubated at $37^{\circ} \mathrm{C}$ for $24 \mathrm{~h}$. Diameter of the swim in the presence and absence of AgNPs was measured. ${ }^{24}$

\subsection{Biofilm inhibition assay}

2.10.1. Effect on biofilm formation. Test pathogens $L$. monocytogenes and L. innocua were cultured overnight in TSB. Overnight grown bacteria were diluted in wells containing fresh Tryptic soy broth corresponding to approx. $1 \times 10^{9} \mathrm{CFU} \mathrm{ml}^{-1}$, $0.5 \times$ MIC of TN-AgNPs was added to wells and incubated at $37{ }^{\circ} \mathrm{C}$ for a day. Post incubation, all wells were emptied to remove unattached cells and all wells were washed with sterile water. Subsequently, $1 \%$ crystal violet was used to stain bound cells and incubated for $15 \mathrm{~min}$. Crystal violet was decanted and the wells were washed to remove excess stain. Crystal violet was dissolved in ethanol $(200 \mu \mathrm{l})$ and absorbance was read at $585 \mathrm{~nm}$ to determine the biofilm inhibition. The percent inhibition of biofilms was calculated using below equation:

$$
\% \text { inhibition }=\left[1-\frac{\mathrm{OD}_{\mathrm{t}}}{\mathrm{OD}_{\mathrm{c}}}\right] \times 100
$$

where, $\mathrm{OD}_{\mathrm{t}}$ and $\mathrm{OD}_{\mathrm{c}}$ are the absorbances of treated and control samples.

2.10.2. Microscopic examination of biofilm structure. Biofilm architecture of TN-AgNPs treated and untreated test Listeria strains grown on glass coverslips at $37^{\circ} \mathrm{C}$ for $24 \mathrm{~h}$ were visualized using SEM and confocal laser scanning microscopy (CLSM). ${ }^{25}$ For SEM, biofilm was developed on coverslips as mentioned above. Coverslips were stained with glutaraldehyde $(2.5 \%)$ and subsequently dehydrated with a gradient of ethanol. Coverslips were gold coated by sputter coater and analyzed under SEM. Similarly, CLSM analysis was performed by staining 
the coverslip with $0.1 \%$ acridine orange in dark and visualizing under JEOL-JSM 6510 LV confocal laser scanning microscope.

2.10.3. Disruption of mature (pre-formed) biofilms. Effect of $0.5 \times$ MIC of TN-AgNPs on pre-formed biofilms of L. monocytogenes 19114, L. monocytogenes 13932 and L. innocua 33090 was also studied. Test pathogens were allowed to grow in the wells of 96 well microtitre plate (MTP) for $24 \mathrm{~h}$. Post incubation, all medium was aspirated out to remove unbound cells and fresh medium was added. TN-AgNPs $(0.5 \times \mathrm{MIC})$ were added to wells except for the control and MTP was incubated for $24 \mathrm{~h}$. Growth medium was decanted from the wells, cells were washed three times with sterilized distilled water and stained with $0.1 \%$ crystal violet. After removing excess stain ethanol (70\%) was added and absorbance was recorded at $585 \mathrm{~nm} .^{26}$

\subsection{ROS generation}

Strains of Listeria growing exponentially were harvested and centrifuged to obtain metabolically active cells. Washed cells were added to fresh TSB medium, 2,7-dichlorofluorescein diacetate (DCFH-DA) was added and cells were left for incubation at shaking for half hour. Thereafter, cells were centrifuged and washed two times to remove the probe. These cells were dispensed into 96-well MTP and AgNPs $(0.5 \times$ MIC) were amended in respective wells. Fluorescent intensity of AgNPs treated and control groups was recorded using fluorescence spectrophotometer (JASCO FP750). ${ }^{27}$

\subsection{Wound healing assay: cell migration analysis}

In vitro scratch/wound healing assay by culturing MCF-7 cells was performed to explore the effect of AgNPs on the cell-cell interaction, and cell migration aspects. ${ }^{28}$ Briefly, equal number $\left(1 \times 10^{6} /\right.$ well) of MCF-7 cells were seeded into respective wells of 24 well culture plates and grown to monolayer confluency. Thereafter, cells were treated with different concentration of AgNPs $\left(0.5-10 \mu \mathrm{g} \mathrm{ml}^{-1}\right)$. A scratch was made in the monolayer with the help of sterile pipette tip. Then unattached cells were decanted by washing with phosphate buffer saline (PBS). Images of control cells (culture medium) and treated cells after $0 \mathrm{~h}, 24 \mathrm{~h}$ and $48 \mathrm{~h}$ were captured on Leica microscope at $20 \times$ magnification.

\subsection{Statistical analysis}

All experiments were done in triplicates and mean values are presented as data. Level of significance was analyzed using Student's $t$-test.

\section{Results}

\subsection{X-ray diffraction analysis of silver nanoparticles}

The crystalline nature of Ag NPs was confirmed by the examining of XRD pattern as shown in Fig. 1A. The XRD spectrum shows prominent peaks at $2 \theta=38.14^{\circ}, 44.12^{\circ}, 64.70^{\circ}$ and $77.43^{\circ}$ representing (111), (200), (220) and (311) Bragg's reflections, respectively. It represents the $F m 3 m$ space group and face centered cubic system with lattice constant $\alpha=4.08 \AA$. The diffraction peaks are broad which signifies the small crystalline size. ${ }^{29}$ The extra peaks near $23.18^{\circ}, 29.37^{\circ}$, and $32.14^{\circ}$ are due to the presence of organic phase on the silver particles. Peaks were matched with a database of Joint Committee on Powder Diffraction Standards (JCPDS) file no. 04-0783. The average size of the Ag nanoparticles was estimated by using the DebyeScherrer equation ${ }^{30}$ and found to be around $81.32 \mathrm{~nm}$.

\subsection{FTIR analysis of silver nanoparticles}

Identification of functional groups and its interaction with the $\mathrm{Ag}$ NPs was analyzed using FTIR spectrometer in the range of 400-4000 $\mathrm{cm}^{-1}$. The spectrum demonstrated that major absorption peaks were recorded at 3448, 2075, 1632, and $667 \mathrm{~cm}^{-1}$, signifying that the molecules of $T$. nilotica extraction act as capping agents that were bound on AgNPs. The absorption peak at region $3448 \mathrm{~cm}^{-1}$ was the reason for -OH stretching vibration of $\mathrm{H}$ bonded alcohol, water, phenols. ${ }^{27}$ The small peak band at $2075 \mathrm{~cm}^{-1}$ and $1631 \mathrm{~cm}^{-1}$ in the spectra corresponds to the $\mathrm{C}-\mathrm{N}$ and $\mathrm{C}-\mathrm{C}$ stretching vibration that contain functional group of nitriles and amines. ${ }^{31}$ The absorption band at $667 \mathrm{~cm}^{-1}$ is due to the presence of $\mathrm{C}-\mathrm{H}$ bend alkynes as shown in Fig. 1B.

\subsection{UV-visible spectroscopy analysis of silver nanoparticles}

Fig. 1C shows the UV-visible spectrum of the dark-brown aqueous AgNP solution. Metal NPs have free electrons, which give a surface plasmon resonance absorption band in the visible range at $431 \mathrm{~nm}$, indicating the formation of AgNPs. ${ }^{32}$

\subsection{Dynamic light scattering (DLS) analysis of silver nanoparticles}

DLS analysis was used to determine the hydrodynamic size, polydispersity index (PDI) and surface zeta potential of the synthesized AgNPs in aqueous environment. Green AgNPs had an average particle size of $131 \mathrm{~nm}$, but the obtained size was higher than the TEM results (Fig. 1D(a)). The PDI value of AgNPs was 0.222 , confirming the polydispersity of AgNPs; PDI $<0.1$ typically indicates monodispersity. The surface zeta potential was negative $(-23.6 \mathrm{mV})$, as shown in Fig. $1 \mathrm{D}(\mathrm{b})$. A high absolute value of the surface zeta potential specifies a high electrical charge on the NP surface, which can cause a strong repellent force among NPs to prevent agglomeration. ${ }^{33}$

\subsection{Morphological analysis of synthesized AgNPs}

Numerous biological agents such as plants and microbes (both bacteria and fungi) have been exploited by researchers for the bio-inspired fabrication of AgNPs. ${ }^{34}$ In the current investigation, the aqueous shoot extract of Tamarix nilotica was used to produce AgNPs. The addition of plant extract to $\mathrm{AgNO}_{3}$ solution resulted in gradual transformation of colorless solution to brown to dark black solution, indicating the formation of AgNPs. $^{35}$

Fig. 2A shows SEM micrograph of AgNPs. As evident from the figure, most of the particles appeared as spherical in nature, a few more spheroidal, and other varying shapes were also observed. The image clearly depicts that there a narrow size 

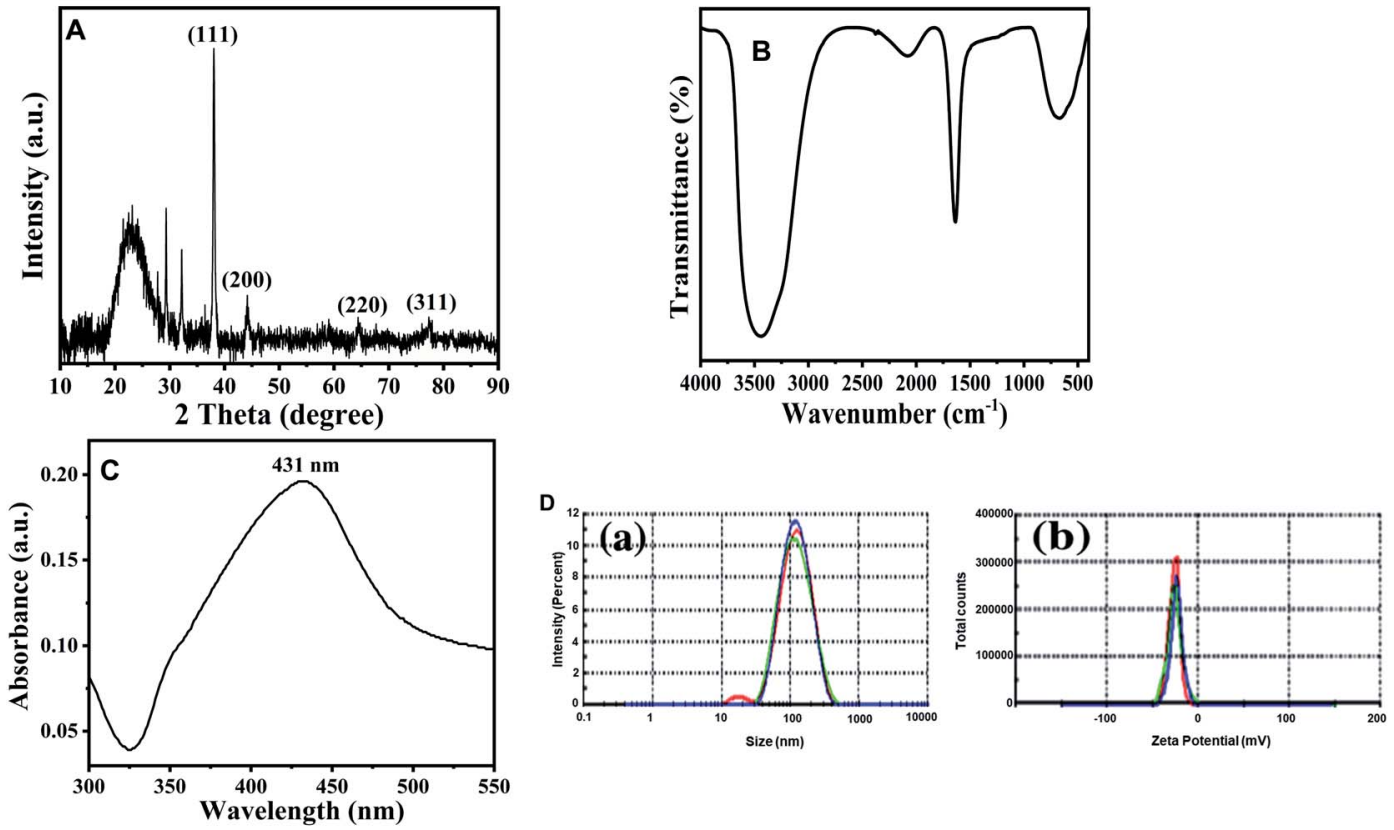

Fig. 1 Characterization of TN-AgNPs. (A) XRD pattern of synthesized AgNPs. (B) FT-IR spectrum of synthesised AgNPs. (C) UV-visible absorbance spectra of as prepared AgNPs. (D) (a) particle size distribution; (b) zeta potential measurement of prepared AgNPs nanoparticles.

distribution with most of the particles of approximately same size. The size and range of silver nanoparticles was further validated using TEM and image is presented in Fig. 2B. The images clearly confirmed that most of particles were spherical with slight variation in size range. The size distribution using TEM was found to be in the 93-121 nm range.

The elemental compositions of AgNPs has been analyzed by EDS, and it is shown in Fig. 2C. The EDS spectrum showed
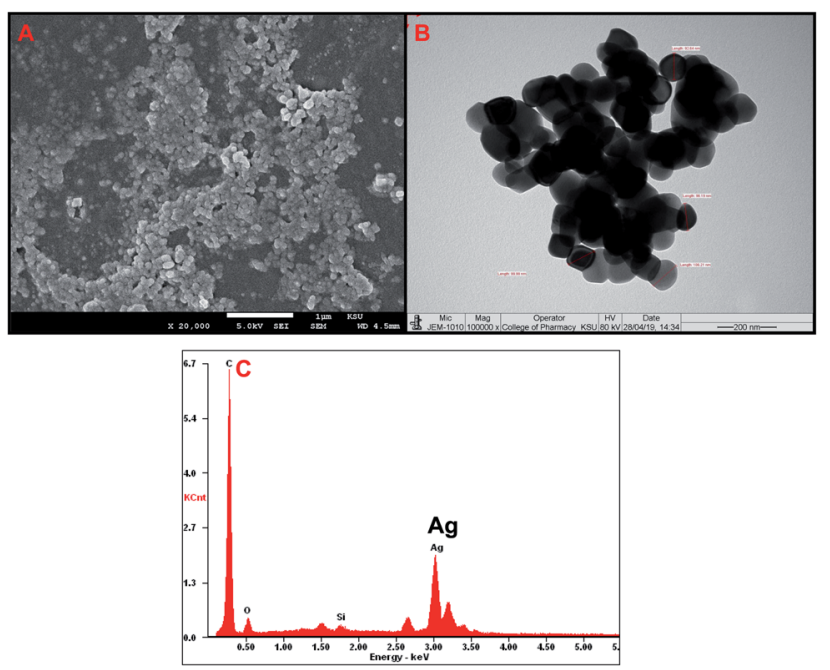

Fig. 2 Characterization of AgNPs using electron microscopy. (A) Scanning electron microscopic (SEM) images of fabricated AgNPs visualized at $20000 \times$. (B) Transmission electron microscopic (TEM) images of fabricated AgNPs visualized at $100000 \times$. (C) EDX spectra of AgNPs. a major peak at $3.0 \mathrm{keV}$, corresponding to $\mathrm{Ag}$ and confirming the presence of AgNPs. The EDS results also demonstrated the presence of $\mathrm{Si}$ and $\mathrm{O}$ elements (Fig. 2C).

\subsection{Antibacterial activity of TN-AgNPs}

3.6.1. MIC and MBC determination. TN-AgNPs were effective as antilisterial agents. The MBC is the lowest concentration that kills $100 \%$ of the bacterial load and does not show any viable growth on agar plates. The MBC for TN-AgNPs against $L$. monocytogenes ATCC 19114, L. monocytogenes ATCC 13932, and L. innocua 33090 was 32,64 , and $32 \mu \mathrm{g} \mathrm{ml}{ }^{-1}$, respectively (Fig. 3A).

MIC values observed against all the three Listeria strains is presented in Fig. 3A. MIC values for TN-AgNPs against $L$. monocytogenes 19114 and L. monocytogenes 13932 was found to be 16 and $32 \mu \mathrm{g} \mathrm{ml}{ }^{-1}$ while L. innocua demonstrated MIC of $16 \mu \mathrm{g}$ $\mathrm{ml}^{-1}$. Our findings find support from the observations made with AgNPs synthesized from the outer peel extract of Ananas comosus. AgNPs demonstrated a slightly higher MIC and MBC values of 50 and $100 \mu \mathrm{g} \mathrm{ml}{ }^{-1}$ respectively, against L. monocytogenes.$^{36}$ Moreover, a similar observation was recorded earlier where AgNPs synthesized from the aqueous leaf extract of Murraya koenigii exhibited MICs as 32, 16, and $64 \mu \mathrm{g} \mathrm{ml}^{-1}$ against methicillin-resistant S. aureus (MRSA), E. coli, and ES $\beta \mathrm{L}-$ producing E. coli. ${ }^{12}$ In another study, AgNPs synthesized from the extract of Phyla dulcis were found effective against $E$. coli O157:H7, drug-resistant $S$. typhimurium, L. monocytogenes and $S$. aureus. ${ }^{37}$ The differences in the MIC and MBC values may be due to the intrinsic tolerance level of the strains used in the assay, variation in the shape and size of AgNPs and protocol used. 

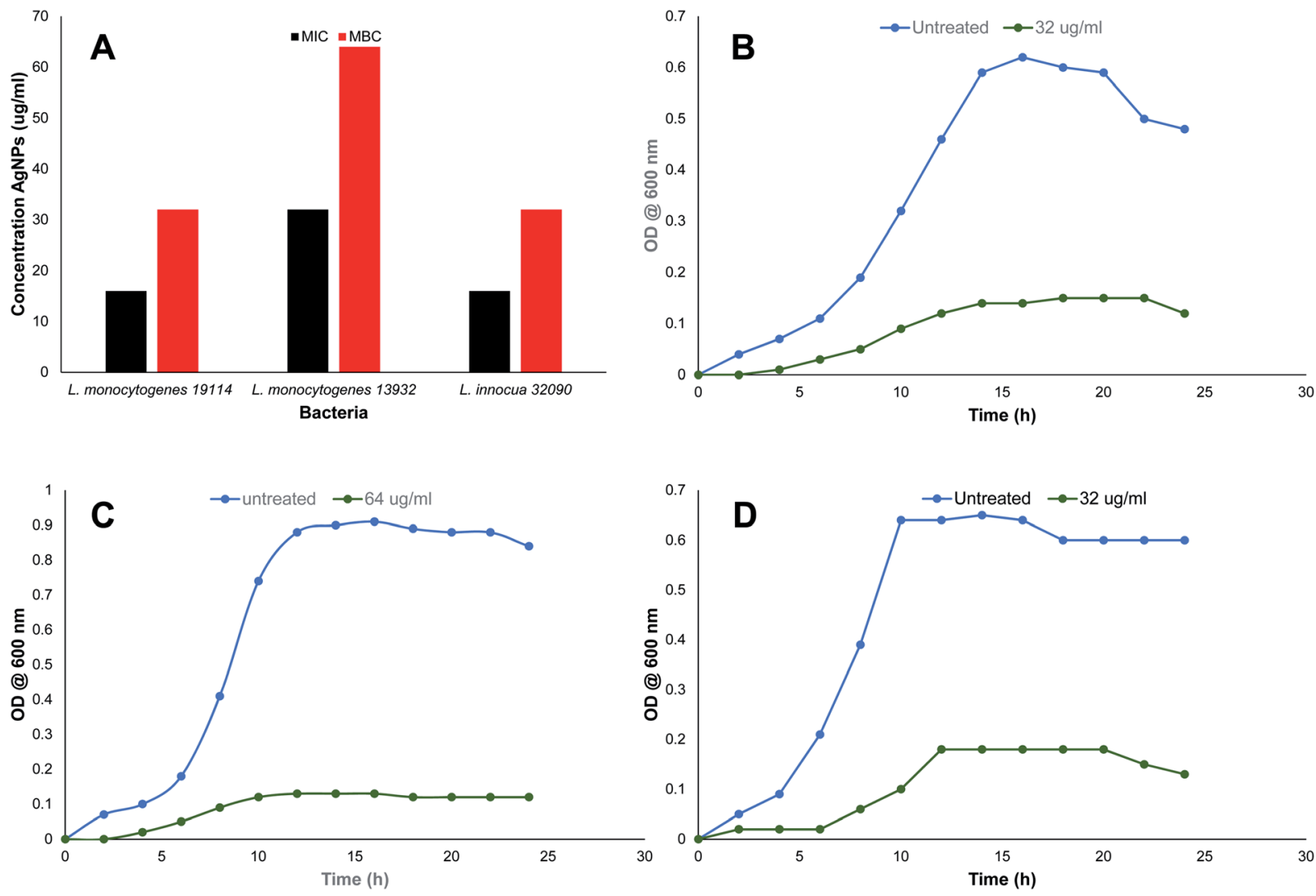

Fig. 3 Antibacterial activity of TN-AgNPs against test strains of Listeria species. (A) MIC and MBC values in $\mu g \mathrm{ml}^{-1}$ of TN-AgNPs. Growth kinetics of (B) Listeria monocytogenes 11914, (C) L. monocytogenes 13932 and (D) L. innocua 33090.

Effect on bacterial was studied at $2 \times$ MICs while swimming and biofilm assays were performed using sub-MICs $(0.5 \times \mathrm{MIC})$.

3.6.2. Effect on growth kinetics of test Listeria strains. Twice of MIC $(2 \times$ MIC $)$ values were considered to study the effect of synthesized TN-AgNPs on the growth of L. monocytogenes 19114, L. monocytogenes 13932 and L. innocua 33090. Growth was examined every two hours for both AgNP treated and untreated (control) by measuring absorbance at $600 \mathrm{~nm}$. Fig. 3B-D very clearly depicts the significant growth inhibitory activity of the TN-AgNPs against the all three test bacteria. Extent of growth inhibition was calculated in terms of percent reduction as compared to untreated control and 74.5, 86 and $70 \%$ growth inhibition was recorded against $L$. monocytogenes 19114, L. monocytogenes 13932 and L. innocua 33090, respectively, at their respective $2 \times$ MICs. Similarly, large-sized AgNPs bio-synthesized from extract of Angelica keiskei demonstrated effective bactericidal activity at $2 \times \mathrm{MIC}$ against L. monocytogenes. ${ }^{38}$ The effect of AgNPs on the growth kinetics of drugresistant bacteria have also been previously studied. A study found that there was $31.4 \%, 53.3 \%$, and $85.6 \%$ reduction in growth of methicillin-resistant $S$. aureus (MRSA) in the presence of 8,16 , and $32 \mu \mathrm{g} \mathrm{ml}{ }^{-1}$ AgNPs. Similarly, the treatment with same concentrations of AgNPs inhibited the growth of ES $\beta$ Lproducing $E$. coli by $21.3 \%, 57.4 \%$, and $60.4 \% .{ }^{12}$ Growth kinetics study was used to assess the antibacterial potential of Captidis rhizome-biosynthesized AgNPs against E. coli and $S$. aureus. Concentration-dependent decrease in the growth of the pathogens was recorded upon treatment with the biosynthesized AgNPs. ${ }^{39}$ Potent antibacterial property of AgNPs has been credited to the release of $\mathrm{Ag}^{+}$ions, direct damage of cell membrane and/or generation of ROS. ${ }^{17}$

3.6.3. SEM analysis of cell morphology. SEM analysis of untreated cultures (control) and AgNPs treated cultures was undertaken to study the effect on cell morphology. The results presented in Fig. 4B and D show clumping of cells, distorted morphology due to rupturing of the cell membrane in cells treated with AgNPs. However, untreated (control) bacteria demonstrated regular cell morphology (Fig. 4A and C). SEM images clearly indicate at the incorporation of silver ions on the cell membrane leading to lysis of the target bacteria.

3.6.4. Loss of cellular content. Release of intracellular content from the bacteria is useful in determining the integrity of the cell membrane i.e. if the membrane of the bacteria is compromised release of the cytoplasmic constituents will be released out of the cell. ${ }^{40}$ Cell membrane has been suggested as one of the prime targets of the AgNPs, information on the loss of cellular content could be an important evidence in understanding the mechanism of action of these NPs. Release of cellular content in the treated and untreated cell filtrates was examined by reading absorbance at $260 \mathrm{~nm}$. Treatment with $2 \times$ MICs of TN-AgNPs resulted in significant increase in the released cellular content (Fig. 5). The findings of the SEM 


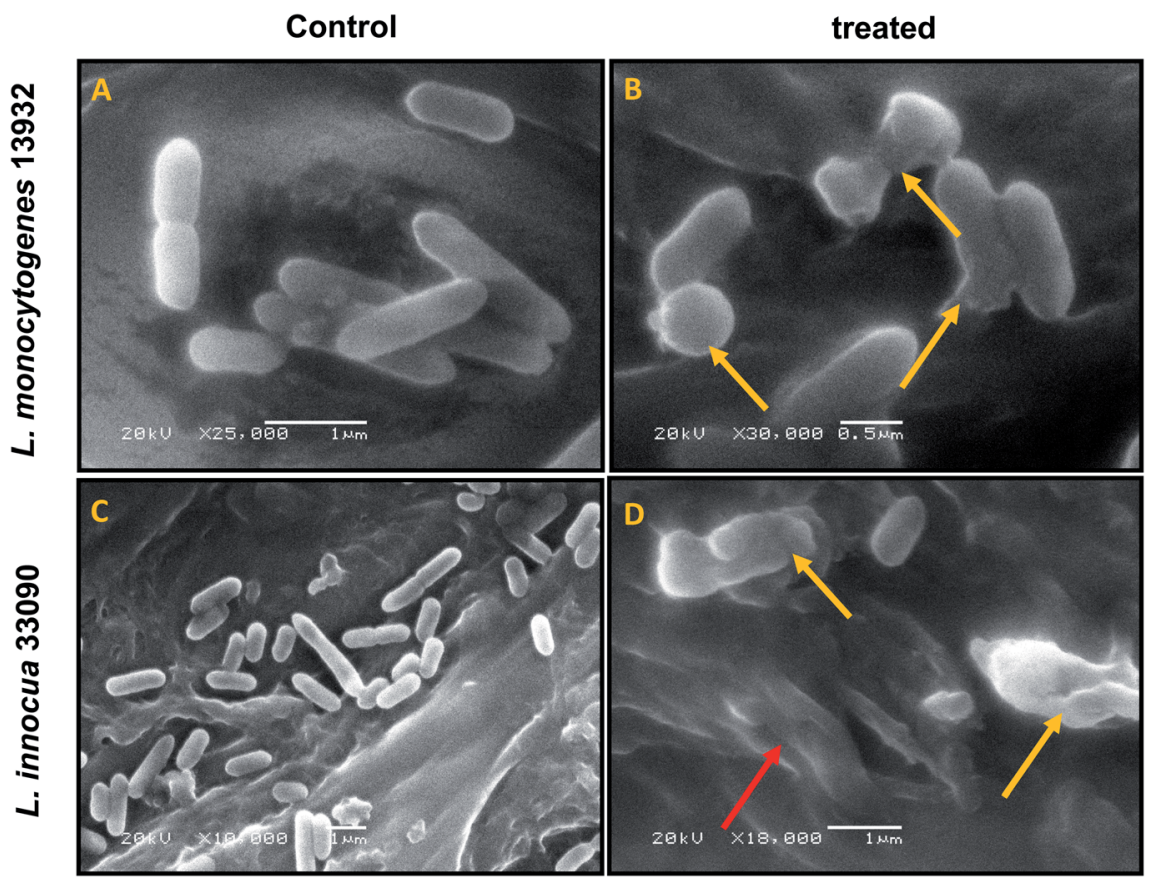

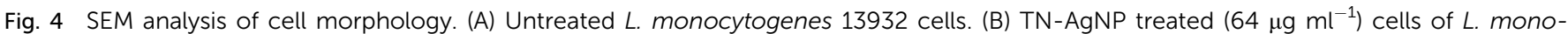
cytogenes. (C) Untreated L. innocua 33090. (D) AgNP treated $\left(32 \mu \mathrm{g} \mathrm{ml}^{-1}\right)$ cells of L. innocua 33090. Yellow arrows indicate distortion of cells and red arrow shows clumping of cells.

analysis integrated with the observed release of cellular content, demonstrates that AgNPs interact strongly with the cells of the Listeria spp. leading to membrane damage, release of intracellular content resulting in cell death.

\subsection{Swimming motility}

Influence of sub-MICs of synthesized TN-AgNPs was examined on the swimming behavior of test the Listeria strains. Swimming motility of all the three test pathogens was impaired significantly $(p \leq 0.05)$ at tested sub-MICs as compared to their untreated controls (Fig. 6). Swimming motility was reduced by 71, 62 and 66\% in L. monocytogenes $19114\left(8 \mu \mathrm{g} \mathrm{m}{ }^{-1}\right), L$. monocytogenes $\left.13932(16 \mu \mathrm{g} \mathrm{ml})^{-1}\right)$ and L. innocua $33090(8 \mu \mathrm{g}$ $\mathrm{ml}^{-1}$ ), respectively. Reports have indicated about the positive role that motility plays in the formation of biofilm by L. monocytogenes as before attachment the bacteria has to travel to the surface of the host. ${ }^{6}$ Our observations showed significantly reduced motility in all the test strain as the AgNPs might be interfering with the flagellin synthesis and this could result in reduced biofilm formation in the under study bacteria.

\subsection{Effect on biofilm formation}

Biofilm forming potential of the three test strains of Listeria species was assessed in the presence of their respective sub-MIC
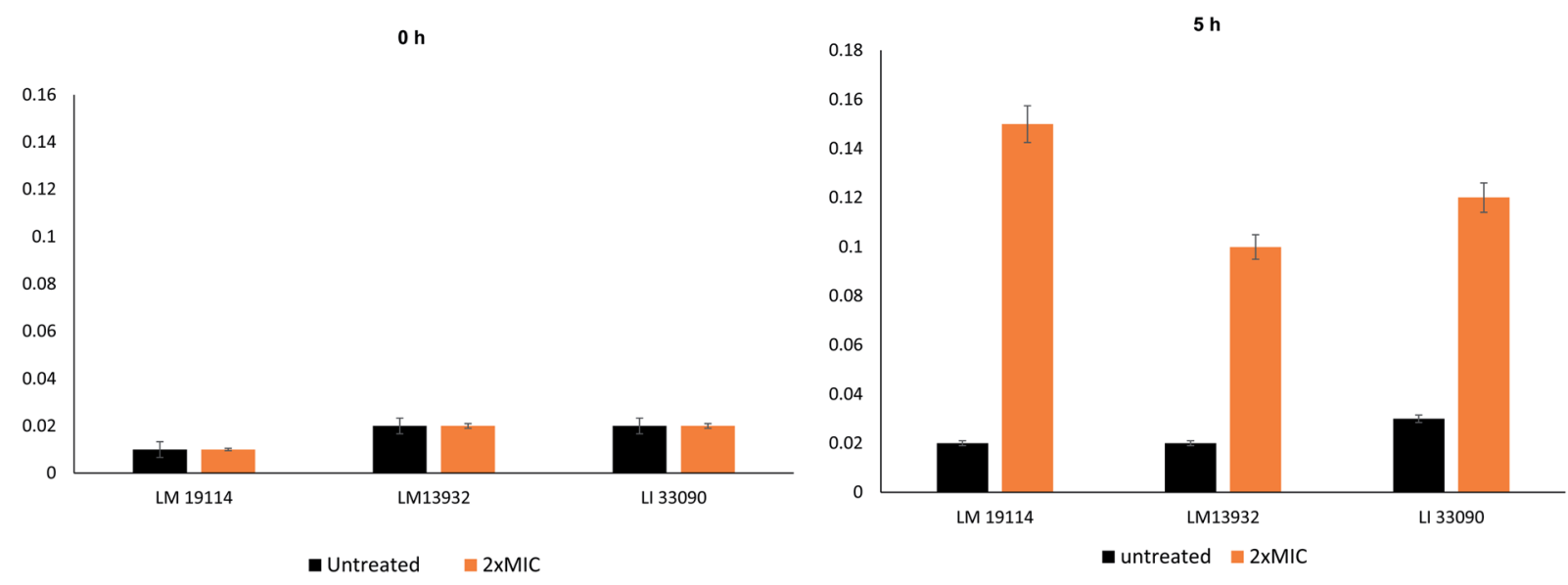

Fig. 5 Cellular content release of test Listeria strains at time $0 \mathrm{~h}$ and $5 \mathrm{~h}$. 


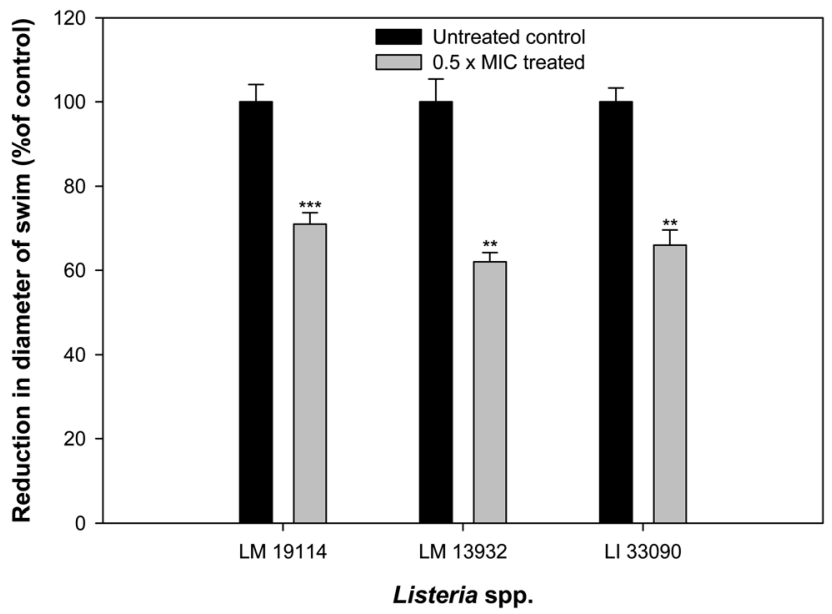

Fig. 6 Effect of $0.5 \times$ MICs of TN-AgNPs on the swimming motility of test strains of Listeria species. Results are depicted as percentage reduction as compared to the untreated control. ** $(p \leq 0.05)$ and *** $(p \leq 0.01)$

of TN-AgNPs. Biofilm formation in all the test strains was impaired significantly upon treatment with the TN-AgNPs as compared to their untreated controls (Fig. 7). There was 62\% and $64 \%$ reduced biofilm formation in the presence of $8 \mu \mathrm{g}$ $\mathrm{ml}^{-1}$ of TN-AgNPs in L. monocytogenes 19114 and L. innocua 33090 , respectively. While, at $16 \mu \mathrm{g} \mathrm{ml}{ }^{-1}$ concentration TNAgNPs decreased the biofilm formation by $57 \%$ in L. monocytogenes 13932. The tested pathogens are proven biofilm formers that makes them dangerous as an infection causing bacteria leading to several health hazards and economic losses. ${ }^{\mathbf{8}}$ Although there is no dearth of information on the antibacterial action of AgNPs but only few reports are available regarding biofilm inhibitory potential of AgNPs against Listeria species. In a recent report, AgNPs containing polyester surface exhibited effective inhibition of biofilm formed by L. monocytogenes at concentration of 500 ppm. ${ }^{41}$ The AgNPs have been wide

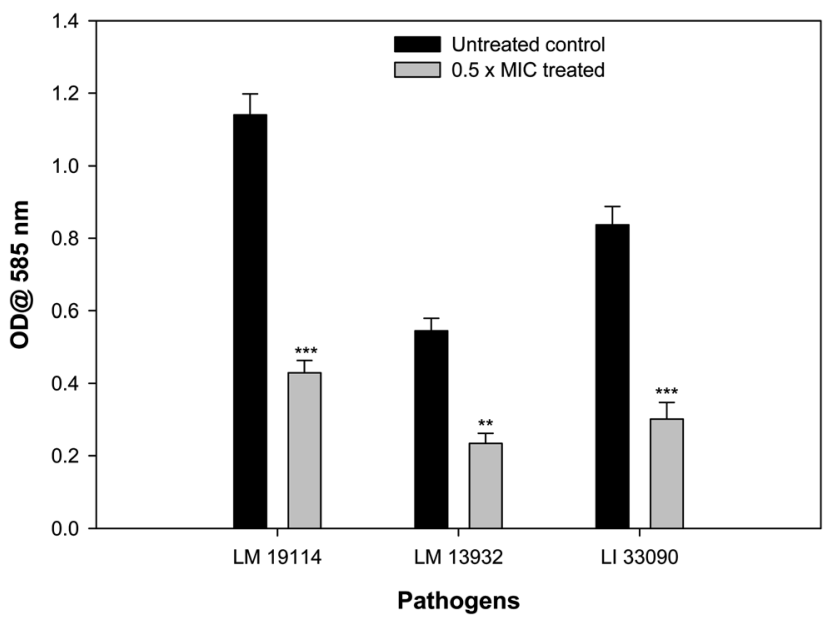

Fig. 7 Effect of $0.5 \times$ MICs of TN-AgNPs on biofilm formation of test strains of Listeria species. Results are depicted as percentage reduction. $* *(p \leq 0.05)$ and $* * *(p \leq 0.01)$. reported for antibiofilm activity in literature. For instance, AgNPs synthesized using aqueous extract of Withania somnifera reduced the biofilms development of $S$. aureus, $S$. mutans, $P$. aeruginosa, and $S$. typhimurium by $40,54,48$, and 50.72 , respectively, compared their respective untreated controls. ${ }^{27}$ Moreover, nanoparticles of iron oxide, tin oxide, gold, copper and organosilane have also been shown to inhibit biofilm of $L$. monocytogenes. ${ }^{\mathbf{4 2 - 4 6}}$ This is probably the first report on the inhibition of biofilm formation in Listeria species by green synthesized AgNPs.

\subsection{Visualization of biofilm inhibition on glass coverslips}

Data obtained by the microtitre plate assay was further validated by examining biofilm formed on glass coverslips. SEM and CLSM images of biofilm of AgNPs treated $(0.5 \times$ MIC) and untreated (control) were analyzed as depicted in Fig. 8 and 9. Scanning electron micrographs (Fig. 8A and B) show extensive formation of biofilm by untreated $L$. monocytogenes 13932 and $L$. innocua 33090. These untreated rod shaped cells are found embedded in dense EPS layer as clumped and clustered cell mass. On the contrary, micrograph of AgNP treated cells (Fig. 8c and d) clearly shows diminished colonization, less aggregation and reduced EPS. A disturbed biofilm architecture is observed in the AgNPs treated cells. Thus, SEM images provide a visual evidence about reduced biofilm formation in treated test strains of Listeria at sub-MICs. CLSM images also corroborate well with the findings of the quantitative data obtained for biofilm inhibition. Dense cell clusters in the untreated controls (Fig. 9a and b) were formed on the glass coverslips. While, in the presence of sub-MICs of AgNPs, cell clusters were greatly reduced and

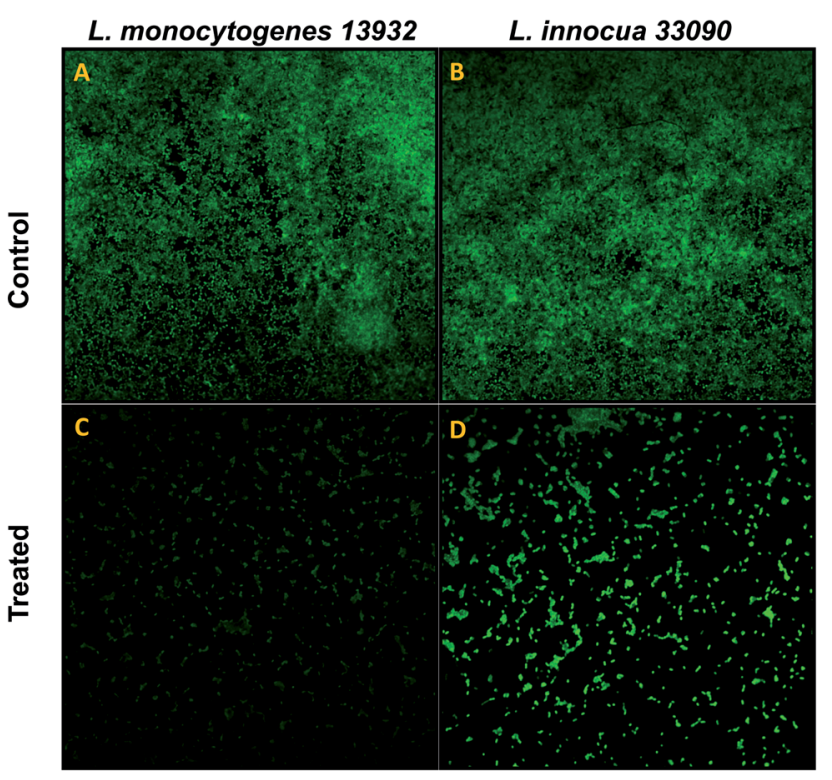

Fig. 8 Confocal laser scanning microscopic (CLSM) analysis of biofilm inhibition (scale bar $=10 \mu \mathrm{m}$ ), stained with acridine orange. (A) Untreated (control) biofilm of L. monocytogenes 13932. (C) L. monocytogenes 13932 treated with $16 \mu \mathrm{g} \mathrm{ml}^{-1}$ of TN-AgNPs. (B) Untreated (control) biofilm of L. innocua 33090. (D) L. innocua 33090 treated with $8 \mu \mathrm{g} \mathrm{ml}^{-1}$ of TN-AgNPs. 


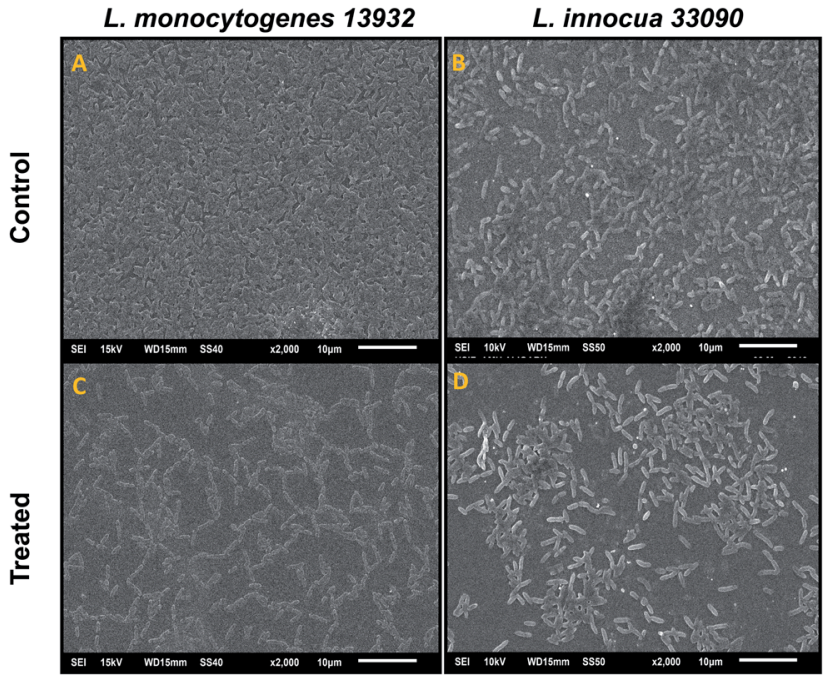

Fig. 9 Scanning electron microscopic (SEM) analysis of biofilm inhibition. (A) Untreated (control) biofilm of L. monocytogenes 13932. (C) L. monocytogenes 13932 treated with $16 \mu \mathrm{g} \mathrm{ml}^{-1}$ of TN-AgNPs. (B) Untreated (control) biofilm of L. innocua 33090. (D) L. innocua 33090 treated with $8 \mu \mathrm{g} \mathrm{ml}^{-1}$ of TN-AgNPs.

considerably less colonization of cells was observed (Fig. 9c and d).

\subsection{Disruption of pre-formed biofilm}

Bacteria residing in biofilm mode are almost thousand times more tolerant to the action of antibiotics, disinfectants and detergents than the free living bacteria. ${ }^{47}$ Therefore, eradication of pre-formed biofilms is a difficult proposition. TN-AgNPs were assessed for their ability to disrupt pre-formed biofilms at subMICs $(0.5 \times$ MIC). The results showed that at respective $0.5 \times$ MIC of TN-AgNPs, $48 \%, 53 \%$ and $58 \%$ reduction in the pre-formed biofilms of L. monocytogenes 19114, L. monocytogenes 13932

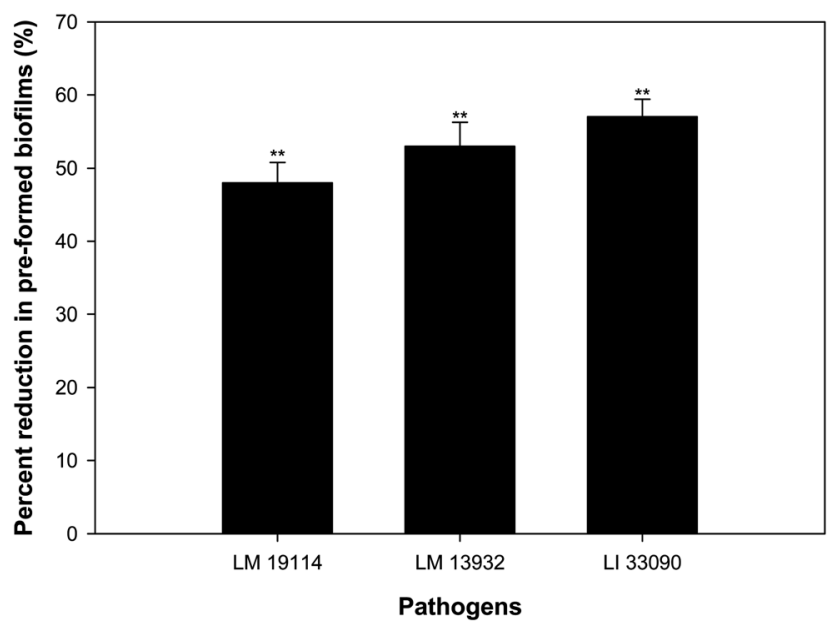

Fig. 10 Inhibitory effect of sub-MICs $(0.5 \times \mathrm{MIC})$ of TN-AgNPs on the pre-formed biofilms of test strains of Listeria spp. Results are depicted as percentage reduction in comparison to untreated control. ** ( $p \leq$ $0.05)$. and L. innocua 33090 was recorded, respectively (Fig. 10). Biofilm cells are enclosed in matrix of EPS, which makes the cells resistant to the action of drugs, disinfectants, biocides and metal ions by preventing their entry ${ }^{48}$ Significant drop in the pre-formed biofilms of all tested strains of Listeria upon treatment with TN-AgNPs revealed that the synthesized NPs could successfully breach the EPS barrier and disrupt established biofilms. This probably the first report on the disruption of preformed biofilms of Listeria species by AgNPs synthesized from plant material.

\subsection{Effect on ROS generation}

The potential of sub-MICs of TN-AgNPs to induce ROS production in the three strains of Listeria was assessed using fluorescent probe DCFH-DA. Significant amount of ROS generation was recorded in AgNPs treated cells as compared to their untreated controls (Fig. 11). ROS levels increased by $62 \%$ in $L$. monocytogenes 19114, while an upsurge of $86 \%$ was recorded in other test strain of L. monocytogenes (LM 13932). L. innocua 33090 exposed to sub-MIC $\left(8 \mu \mathrm{g} \mathrm{ml}{ }^{-1}\right)$ of TN-AgNPs exhibited $48 \%$ elevated ROS levels. Production of ROS in nanoparticle treated cells surpasses the capacity of antioxidant defense system leading to oxidative stress that starts lipid peroxidation. As a result, cell death occurs due to the damage to cell membrane. ${ }^{49}$ Thus, ROS generation by AgNPs is a key mechanism in the inhibition of biofilm.

\subsection{Wound healing assay: cell migration analysis}

Wound healing or scratch assay is a robust and most commonly used method to probe cell migration. ${ }^{50}$ In this study, MCF-7 cells were subjected to wound healing assay under the influence of different concentration of AgNPs $\left(0.5-10 \mu \mathrm{g} \mathrm{ml}{ }^{-1}\right)$. Scratch plate assay showed that the AgNPs at all tested concentration impaired the cell migration effectively (Fig. 12). Further, our result showed concentration and time dependent inhibition on the migration of cells. At lower concentration $\left(0.5-2 \mu \mathrm{g} \mathrm{ml}{ }^{-1}\right)$ of AgNPs, less cytotoxicity and inhibition of

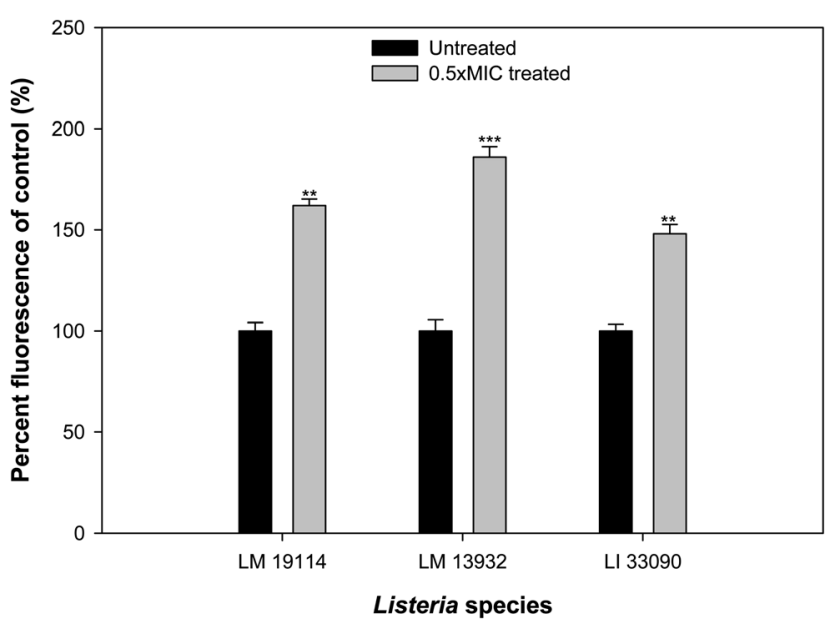

Fig. $11 \mathrm{TN}-\mathrm{AgNPs}$ induced ROS generation in the sub-MICs treated and untreated test bacteria. $* *(p \leq 0.05)$ and $* * *(p \leq 0.01)$. 


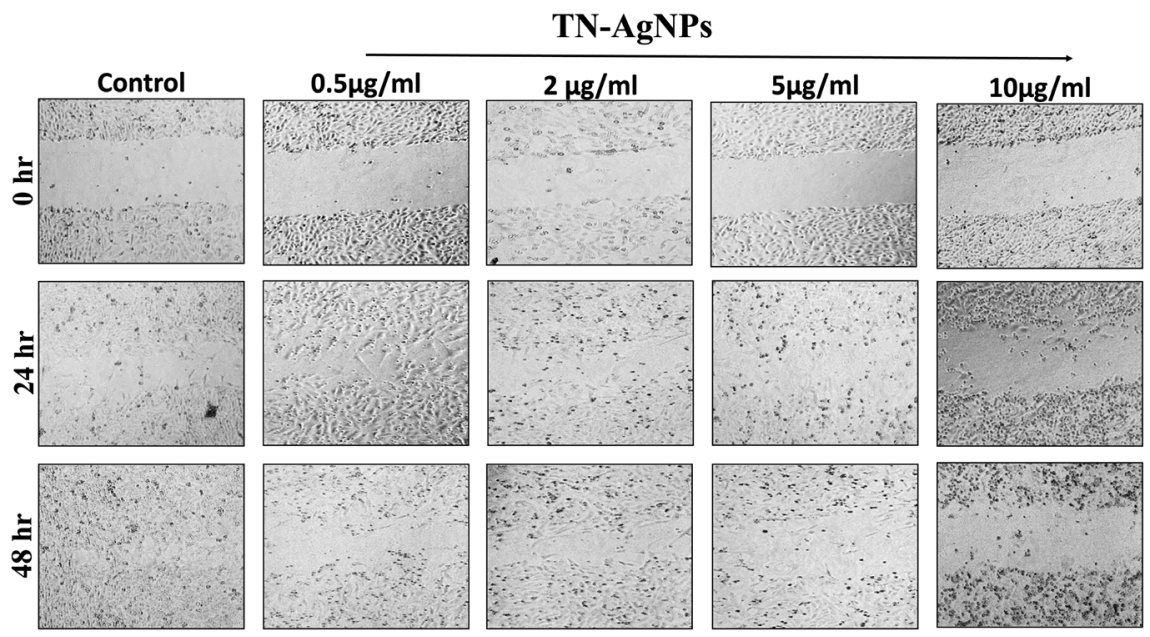

Fig. 12 Wound healing assay to assess the migration of TN-AgNPs treated and untreated MCF-7 cells through scratch assay. Images were captured at 0,24 and $48 \mathrm{~h}$.

migration was observed. However, its higher concentration (5$10 \mu \mathrm{g} \mathrm{ml}^{-1}$ ) causes more cytotoxicity and distinct inhibition of migration of cells. As cytoskeleton rearrangements are crucial for cell migration, it is noteworthy to speculate that AgNPs might interfere with this process reaffirming earlier report. ${ }^{51}$ Since cell division requires cytoskeleton rearrangement, effect of AgNPs on cell proliferation can also be seen in Fig. 12. At 5 and $10 \mu \mathrm{g} \mathrm{ml}^{-1} \mathrm{AgNPs}$ after 48 hours, reduction in cell number was observed as compared to untreated control. Tested concentrations of the synthesized AgNPs significantly effect cell proliferation and migration. Our results corroborate well with the previous literature reporting the inhibitory effect of nanoparticles on the migration of cancer cells..52 Moreover, our cytotoxicity analysis revealed the effectiveness of AgNPs between $0.5-10 \mu \mathrm{g} \mathrm{ml} \mathrm{ml}^{-1}$, which is in line with previous studies. ${ }^{53,54}$ From the present findings, it is envisaged that not only the TN-AgNPs will speed up the healing process but also prevents the colonization of bacteria in wounds as it possesses both antibacterial and antibiofilm properties.

\section{Conclusion}

The study showcases the efficiency of extract of in vitro grown $T$. nilotica shoot to fabricate silver nanoparticles (AgNPs) without using any hazardous chemical. The characterized AgNPs demonstrated significant inhibition of bacterial growth of three test strains of Listeria. SEM images demonstrated that the AgNPs caused distortion of cell morphology leading to cell death. Further, the synthesized AgNPs significantly impaired biofilm formation as well as disrupted pre-formed biofilms at sub-MICs. Finding of the biofilm inhibition were also confirmed by SEM and CLSM analysis. Interaction of bacterial cells in and sub-MICs of AgNPs leads to production of excessive ROS causing cell death and subsequently inhibition of biofilms. In addition to the antibacterial and antibiofilm action, synthesized AgNPs exhibited effective wound healing potential. Therefore, the findings of investigation advocates that the synthesized AgNPs can be exploited as an alternative or supplementary strategy to mitigate the contamination and infection caused by L. monocytogenes.

\section{Conflicts of interest}

The authors declare no conflict of interest.

\section{Acknowledgements}

The authors extend their appreciation to Deanship of Scientific Research at King Saud University for funding this work through Research Group No. RGP-1439-014. The authors thank the Deanship of Scientific Research and RSSU at King Saud University for their technical support.

\section{References}

1 X. Miao, H. Liu, Y. Zheng, D. Guo, C. Shi, Y. Xu and X. Xia, Front. Cell. Infect. Microbiol., 2019, 9, 304, DOI: 10.3389/ fcimb.2019.00304.

2 Q. Zhu, R. Gooneratne and M. Hussain, Foods, 2017, 6, 21.

3 A. Parisi, L. Latorre, G. Normanno, A. Miccolupo, R. Fraccalvieri, V. Lorusso and G. Santagada, Food Microbiol., 2010, 27, 101-108.

4 S. Lomonaco, D. Nucera, A. Parisi, G. Normanno and M. T. Bottero, Int. J. Food Microbiol., 2011, 149, 177-182.

5 S. Belluco, C. Losasso, I. Patuzzi, L. Rigo, D. Conficoni, F. Gallocchio, V. Cibin, P. Catellani, S. Segato and A. Ricci, Food Microbiol., 2016, 7, 1-9.

6 K. P. Lemon, D. E. Higgins and R. Kolter, J. Bacteriol., 2007, 189, 4418-4424.

7 J. W. Costerton, P. S. Stewart and E. P. Greenberg, Science, 1999, 284, 1318-1322.

8 J. A. Vázquez-Boland, M. Kuhn, P. Berche, T. Chakraborty, G. Domínguez-Bernal, W. Goebel, B. González-Zorn, 
J. Wehland and J. Kreft, Clin. Microbiol. Rev., 2001, 14, 584640.

9 I. Hasan, F. A. Qais, F. M. Husain, R. A. Khan, A. Alsalme, B. Alenazi, M. Usman, M. H. Jaafar and I. Ahmad, J. Cleaner Prod., 2019, 230, 1148-1155.

10 C. K. Tagad, S. R. Dugasani, R. Aiyer, S. Park, A. Kulkarni and S. Sabharwal, Sens. Actuators, B, 2013, 183, 144-149.

11 V. L. Das, R. Thomas, R. T. Varghese, E. V. Soniya, J. Mathew and E. K. Radhakrishnan, 3 Biotech, 2014, 4, 121-126.

12 F. A. Qais, A. Shafiq, H. M. Khan, F. M. Husain, R. A. Khan, B. Alenazi, A. Alsalme and I. Ahmad, Bioinorg. Chem. Appl., 2019, 2019, 4649506.

13 X. F. Zhang, Z. G. Liu, W. Shen and S. Gurunathan, Int. J. Mol. Sci., 2016, 17, 1534.

14 S. Venkat Kumar and S. Rajeshkumar, Plant-Based Synthesis of Nanoparticles and Their Impact, Elsevier Inc., 2018, vol. 1.

15 M. K. Rajesh, K. S. Muralikrishna, S. S. Nair, K. B. Krishna,

T. M. Subrahmanya, K. P. Sonu, K. Subaharan, H. Sweta, P. T. S. Keshava, C. Neeli, I. Karunasagar, K. B. Hebbar and A. Karun, Mater. Sci. Eng., C, 2020, 111, 110834, DOI: 10.1016/j.msec.2020.110834.

16 S. Kulshrestha, S. Qayyum and A. U. Khan, Microb. Pathog., 2017, 103, 167-177.

17 S. Prabhu and E. K. Poulose, Int. Nano Lett., 2012, 2, 32-41. 18 S. Abouzid and A. Sleem, Pharm. Biol., 2011, 49, 392-395.

19 F. Al-Qurainy, M. Nadeem, S. Khan, M. Tarroum and S. Alansi, Pak. J. Bot., 2015, 47, 2355-2359.

20 A. Nabikhan, K. Kandasamy, A. Raj and N. M. Alikunhi, Colloids Surf., B, 2010, 79, 488-493.

21 H. Chen and Q. Zhong, Int. J. Food Microbiol., 2017, 260, 3641.

22 K. Rhayour, T. Bouchikhi, A. Tantaoui-Elaraki, K. Sendide and A. Remmal, J. Essent. Oil Res., 2003, 15, 286-292.

23 E. Sorrentino, P. Tremonte, M. Succi, M. Iorizzo, G. Pannella, S. J. Lombardi, M. Sturchio and R. Coppola, Food Microbiol., 2018, 9, 1-9.

24 N. A. Al-Shabib, F. M. Husain, M. T. Rehman, A. A. Alyousef, M. Arshad, A. Khan, J. Masood Khan, P. Alam, T. A. Albalawi, S. A. Shahzad, J. B. Syed and M. F. Al-ajmi, Saudi J. Biol. Sci., 2020, 27, 1080-1090.

25 N. A. Al-Shabib, F. M. Husain, R. A. Khan, M. S. Khan, M. Z. Alam, F. A. Ansari, S. Laeeq, M. Zubair, S. A. Shahzad, J. M. Khan, A. Alsalme and I. Ahmad, Saudi J. Biol. Sci., 2019, 26, 308-316.

26 S. Gaidhani, R. Singh, D. Singh, U. Patel, K. Shevade, R. Yeshvekar and B. Ananda Chopade, Mater. Lett., 2013, 108, 324-327.

27 F. A. Qais, Samreen and I. Ahmad, IET Nanobiotechnol., 2018, 12, 325-335.

28 L. G. Rodriguez, X. Wu and J.-L. Guan, in Cell Migration, Humana Press, New Jersey, 2005, pp. 023-030.

29 D. Nayak, S. Ashe, P. R. Rauta, M. Kumari and B. Nayak, Mater. Sci. Eng., C, 2016, 58, 44-52.

30 B. Cullity, Elements of X-ray diffraction, Addison-Wesley Publishing Company, Inc., Reading, MA, 1978.

31 K. Jyoti, M. Baunthiyal and A. Singh, J. Radiat. Res. Appl. Sci., 2016, 9, 217-227.
32 N. Vigneshwaran, N. M. Ashtaputre, P. V. Varadarajan, R. P. Nachane, K. M. Paralikar and R. H. Balasubramanya, Mater. Lett., 2007, 61, 1413-1418.

33 R. Sankar, A. Karthik, A. Prabu, S. Karthik, K. S. Shivashangari and V. Ravikumar, Colloids Surf., B, 2013, 108, 80-84.

34 S. Iravani, Green Chem., 2011, 13, 2638.

35 S. Gurunathan, K. Kalishwaralal, R. Vaidyanathan, D. Venkataraman, S. R. K. Pandian, J. Muniyandi, N. Hariharan and S. H. Eom, Colloids Surf., B, 2009, 74, 328-335. 36 G. Das, J. K. Patra, T. Debnath, A. Ansari and H. S. Shin, PLoS One, 2019, 14, 1-19.

37 L. Carson, S. Bandara, M. Joseph, T. Green, T. Grady, G. Osuji, A. Weerasooriya, P. Ampim and S. Woldesenbet, Foodborne Pathog. Dis., 2020, 17, 1-8.

38 J. Du, Z. Hu, W. jie Dong, Y. Wang, S. Wu and Y. Bai, Microchem. J., 2019, 147, 333-338.

39 G. Sharma, J. S. Nam, A. R. Sharma and S. S. Lee, Molecules, 2018, 23, 2268.

40 C. Z. Chen and S. L. Cooper, Biomaterials, 2002, 23, 33593368.

41 F. Fontecha-Umaña, A. G. Ríos-Castillo, C. Ripolles-Avila and J. J. Rodríguez-Jerez, Foods, 2020, 9, 442-456.

42 N. A. Al-Shabib, F. M. Husain, F. Ahmed, R. A. Khan, M. S. Khan, F. A. Ansari, M. Z. Alam, M. A. Ahmed, M. S. Khan, M. H. Baig, J. M. Khan, S. A. Shahzad, M. Arshad, A. Alyousef and I. Ahmad, Food Microbiol., 2018, 9, 2567.

43 N. A. Al-Shabib, F. M. Husain, N. Ahmad, F. A. Qais, A. Khan, A. Khan, M. S. Khan, J. M. Khan, S. A. Shahzad and I. Ahmad, J. Nanomater., 2018, 2018, 1-11.

44 H. Mu, J. Tang, Q. Liu, C. Sun, T. Wang and J. Duan, Sci. Rep., 2016, 6, 1-9.

45 E. Ghasemian, A. Naghoni, H. Rahvar, M. Kialha and B. Tabaraie, Jundishapur J. Microbiol., 2015, 8, 4-8.

46 E. N. Gkana, A. I. Doulgeraki, N. G. Chorianopoulos and G. J. E. Nychas, Food Microbiol., 2017, 8, 1-9.

47 C. A. Fux, J. W. Costerton, P. S. Stewart and P. Stoodley, Trends Microbiol., 2005, 13, 34-40.

48 L. Hall-Stoodley, J. W. Costerton and P. Stoodley, Nat. Rev. Microbiol., 2004, 2, 95-108.

49 H.-L. Su, C.-C. Chou, D.-J. Hung, S.-H. Lin, I.-C. Pao, J.-H. Lin, F.-L. Huang, R.-X. Dong and J.-J. Lin, Biomaterials, 2009, 30, 5979-5987.

50 C.-C. Liang, A. Y. Park and J.-L. Guan, Nat. Protoc., 2007, 2, 329-333.

51 R. J. Cooper and N. Spitzer, Neurotoxicology, 2015, 48, 231238.

52 A. Hussain, M. F. Alajmi, M. A. Khan, S. A. Pervez, F. Ahmed, S. Amir, F. M. Husain, M. S. Khan, G. M. Shaik, I. Hassan, R. A. Khan and M. T. Rehman, Food Microbiol., 2019, 10, 1-19.

53 C. Zanette, M. Pelin, M. Crosera, G. Adami, M. Bovenzi, F. F. Larese and C. Florio, Toxicol. In Vitro, 2011, 25, 10531060 .

54 S. Gurunathan, J. W. Han, V. Eppakayala, M. Jeyaraj and J.-H. Kim, BioMed Res. Int., 2013, 2013, 1-10. 